\title{
Paralytic Strabismus: A Review of 13 Years at a Tertiary Care Center in Western-Central India
}

\author{
Shreya Shah ${ }^{1}$, Mehul Shah ${ }^{1}$, Pradeep Chandane ${ }^{1}$, Sakshi Makhloga ${ }^{1}$, Meera Sanghani ${ }^{1}$, Deeksha Thorat ${ }^{1}$ \\ Drashti Netralaya ${ }^{1 *}$ \\ ${ }^{1}$ Drashti Netralaya Opthalmic Mission Trust, Nr. GIDC, Chakalia Road, Dahod, Gujarat, India \\ *Corresponding Author: Drashti Netralaya, Drashti Netralaya Opthalmic Mission Trust, Nr. GIDC, Chakalia \\ Road, Dahod, Gujarat, India; Email: omtrustdahod@gmail.com
}

Received Date: 30-08-2021; Accepted Date: 16-09-2021; Published Date: 23-09-2021

Copyright $^{\odot} 2021$ by Netralaya D, et al. All rights reserved. This is an open access article distributed under the terms of the Creative Commons Attribution License, which permits unrestricted use, distribution and reproduction in any medium, provided the original author and source are credited.

\begin{abstract}
Purpose: To describe the incidence, aetiologies and follow-up of patients with paralytic strabismus.

Methods: This retrospective study included 193 strabismic patients with isolated III, IV or VI cranial nerve palsy, cases of the strabismus from the Department of Ophthalmology of the tertiary care center in western-central India between January 2007 and December 2020. The present study analyzed the injured cranial nerve, the affected eye, sex distribution, etiology and follow-up.

Results: About $5.7 \%$ of the cases were congenital and $16.1 \%$ were of pediatric age. The Trochlear nerve was the most frequently affected $(56.5 \%)$ in these cases. Incidence was higher in males $(58.1 \%)$ than females. Trauma was the common cause of III (7.1\%), IV (8.3\%) and VI (50\%) nerve palsy. The disease management modalities included surgical, medical and spontaneous resolution.

Conclusions: The sixth cranial nerve was affected most frequently. However, the most common underlying cause was yet undetermined.
\end{abstract}

\section{Keywords}

Paralytic Strabismus; Epidemiology; Strabismus Etiology; Cranial Nerve Palsy

Netralaya D | Volume 2; Issue 3 (2021) | JOAR-2(3)-021 | Research Article

Citation: Netralaya D, et al. COVID-19 Publication and the Future of Research. J Ophthalmol Adv Res.

2021;2(3):1-6.

DOI: http://dx.doi.org/10.46889/JOAR.2021.2302 


\section{Introduction}

Paralysis and paretic strabismus are characterized by weakness of one or more oculomotor muscles innervated by the nerves, resulting in an uncommon deviation that can require clinical and surgical treatment or spontaneous regression [1].

Paralysis or paresis of the cranial nerves III, IV and VI have been analyzed previously and these studies are classic hallmarks [2-5]. Cranial nerve VI has been identified as the most affected region.

The present study aimed to elucidate the epidemiological and clinical profiles of paralytic strabismus and clinical outcome on follow-up with or without management.

\section{Methods}

After clearance from the hospital ethical committee (DN/2020/Dec/21)

This retrospective study analyses the incidence, etiology and evolution of paralytic or paretic strabismus in patients seen in the Strabismus Department of Ophthalmology, India, the data of patients with paralytic paresis or paralysis were obtained from the electronic medical records from 2007 to 2018.

The aetiological factors of the cases were classified into four groups: trauma, vascular anomaly (including systemic diseases such as systemic hypertension, DM and cerebral aneurysm), undetermined (no cause was found after the diagnostic investigation) and others. This grouping facilitated the comparison between the current and previous data since most groups adopt this categorization method. In addition, congenital cases constituted an independent group. Evolution was also divided into five groups: regression spontaneous, surgery (patient undergoing surgery), without follow-up (patient follow-up was lost), still in follow-up and discharge after cure or on request.

Data related to sex, the affected nerve, the affected eye, the etiology and the evolution of acquired paresis and isolated paralysis were collected in the pre-tested format, exported to Excel and analyzed using SPSS 22 (no conflict of interest). Descriptive and cross-tabulation statistics were used to analyze the data. $\mathrm{P}<0.05$ indicated statistical significance.

\section{Results}

The current cohort of 193/66 (34.2\%) females and 127 (65.8\%) males patients with isolated paresis or paralysis of the muscles innervated by the cranial nerves III, IV or VI, correspond to $4.7 \%$ of the patients in the Ocular Motility Section (Table 1). The age of onset of the clinical manifestations of the group with paralytic strabismus or acquired paretic was between 1 and 85 years. The congenital cases were studied separately; 11/193 (5.7\%) patients were congenital 
cases and the remaining $182(94.3 \%)$ were acquired paretic $31 / 193(16.1 \%)$ constituted the pediatric age group. The mean follow-up of the patients was 203.30 days.

The right eye was involved in 82/193 (42.5\%), the left eye in $73(37.8 \%)$ and both eyes in 38 $(19.7 \%)$ cases. Our cohort included 2 cases of myasthenia gravis, suggesting a myogenic cause.

Herein, strabismus esotropia was found in 127/193 (65.8\%) cases (Table 2 and 3). Also, 42/193 (21.8\%) cases occurred due to trauma to the cranial nerve or extraocular muscle.

Furthermore, cranial nerve VI was affected in 110/193 (56.9 48.7\%) cases, of which 15 (13.6 $\%)$ were traumatic and 95(86.3\%) were non-traumatic.

Cranial nerve III was affected in 47/193 (24.4\%) cases, of which $16(34 \%)$ were traumatic and $31(66 \%)$ were non-traumatic.

Among the other causes of cranial nerve III palsy, the central nervous system infection was detected in 1 case.

Concerning disease management, 149/193 (77.2\%) received medical treatment, 29 (15\%) received surgical management and $7(3.6 \%)$ were advised but did not undergo surgery. Moreover, $18(9.3 \%)$ cases did not receive treatment, while 7 (3.6\%) were lost to follow-up. When compared significant difference was observed between the first presentation and subsequent visits $(\mathrm{P}=0.05)$.

In the current cohort, 43/193 (22.3\%) exhibited traumatic etiology and no relevant cause was identified in $114 / 193(59.1 \%)$ cases.

The comparison between the deviation in primary position at the time of presentation and the end revealed significant differences $(\mathrm{p}<001)$, but no difference was observed while comparing traumatic and non-traumatic cases $(\mathrm{P}=0.435)$.

\begin{tabular}{|c|c|c|c|}
\hline \multirow{2}{*}{} & \multicolumn{2}{|c|}{ Sex } & \multirow{2}{*}{ Total } \\
\cline { 2 - 3 } & $\mathbf{F}$ & $\mathbf{M}$ & \\
\hline $0-10$ & 7 & 8 & 15 \\
\hline $20-$ Nov & 12 & 13 & 25 \\
\hline $21-30$ & 5 & 31 & 36 \\
\hline $31-40$ & 7 & 20 & 27 \\
\hline $41-50$ & 9 & 22 & 31 \\
\hline $51-60$ & 12 & 20 & 32 \\
\hline $61-70$ & 10 & 11 & 21 \\
\hline$>70$ & 4 & 2 & 6 \\
\hline Total & 66 & 127 & 193 \\
\hline
\end{tabular}

Table 1: Age and sex distribution. 


\begin{tabular}{|c|c|c|}
\hline & Frequency & Percent \\
\cline { 2 - 3 } & 2 & 1 \\
\hline Congenital & 11 & 5.7 \\
\hline Myogenic & 3 & 1.6 \\
\hline Neurogenic & 134 & 69.4 \\
\hline Neurogenic+Myo & 1 & 0.5 \\
\hline Traumatic & 42 & 21.8 \\
\hline Total & 193 & 100 \\
\hline
\end{tabular}

Table 2: Aetiological category.

\begin{tabular}{|c|c|c|}
\hline Type & Frequency & Percent \\
\hline Esotropia & 123 & 63.7 \\
\hline Exotropia & 49 & 25.4 \\
\hline Exotropia+Hypertropi & 5 & 2.6 \\
\hline Exotropia+Hypotropia & 6 & 3.1 \\
\hline Hypertropia & 8 & 4.1 \\
\hline Hypotropia & 2 & 1 \\
\hline Total & 193 & 100 \\
\hline Tabl
\end{tabular}

Table 3: Type of strabismus.

\section{Discussion}

The proportion of gender in the current cohort was similar to that described in the literature. This slight predominance of the male sex could be attributed to the frequency of traumatic causes in this sample [1].

Among the acquired isolated paralysis and paralysis, the most affected cranial nerve was VI (56.9\%), followed by III $(24.4 \%)$ and IV $(1.01 \%)$. These data coincide with those in the literature, wherein nerve VI was most affected with a frequency of $40.9 \%, 51.1 \%, 41.9 \%$ and $55.0 \%$ [2-5]. In a private clinic, which is a reference in strabismus, the frequency of cranial nerve IV involvement was $62.2 \%$; this might be because the clinic is a differentiated reference service [6].

The data related to the affected eye showed a discrepancy between our sample and those in the literature. The right eye was involved in 82/193 (42.5\%) cases, the left eye in $73(37.8 \%)$ cases and both eyes in $38(19.7 \%)$ cases, while Gustavo, et al., reported $49.5 \%$ impairment of the right eye, $41.9 \%$ of the left eye and $8.6 \%$ of bilateral impairment [1]. Regarding paresis or acquired paralysis of cranial nerve III, $8.3 \%$ was traumatic etiology and $59.1 \%$ was due to undetermined causes. Some studies showed that $45.5 \%$ were congenital cases $[7,8]$. Another study found a high frequency of indeterminate cases $(23.7 \%)$, followed by vascular causes (19.8\%) [6]. A previous study also reported a frequency of $40.5 \%$ of undetermined cause and 
$29.2 \%$ of vascular etiology [8]. These differences could be attributed to the demographic properties of the catchment area. The low occurrence of vascular etiology (17.5\%) is probably due to these patients' lack of diagnosis or referral to our department [1].

The cases of paresis or acquired paralysis of the cranial nerve IV incidence is lesser in our cohort $(1.01 \%)$ compared to the higher rate $(52.4 \%)$ reported by Gustavo, et al., wherein $30.5 \%$ cases were classified as the undetermined cause. Literature analysis also revealed that trauma $(25.7 \%)$ and vascular injury $(15.7 \%)$ were the most frequent aetiological factors, while $28.3 \%$ were undetermined causes $[1,7]$. The current study reported $5.7 \%$ congenital cases and $16.1 \%$ cases in the pediatric age group. Other studies reported $43.5 \%$ congenital cases, $38.8 \%$ undetermined causes and $7.6 \%$ cases of traumatic origin $[9,10]$. Another study found $39.5 \%$ congenital cases, $34.0 \%$ traumatic causes and $23.2 \%$ cases of undetermined origin [11]. Some surveys conducted on children demonstrated that $57.3 \%$ of the cases were of unknown cause and $13.6 \%$ were detected during follow-up [12,13]. Previous studies also observed that spontaneous regression occurred in $9.3 \%$ cases and the frequency of these cases was $48.3 \%$ and $66.6 \%$, respectively $[4,9]$.

In the studies described above, vascular etiology cases had the highest rate of spontaneous regression, while this group presented a low frequency in our cohort. In addition, the loss of patients to follow-up, which is common in public hospitals, may have caused a decrease in the frequency of this regression.

Jason, et al., reported a similar outcome irrespective of the etiology, however, the number of surgeries may be more than that in the current study [14]. Kiyoung, et al., also reported that vascular causes display maximum recovery rate and a short recovery time [15].

\section{Conclusion}

Paralytic strabismus is caused by several reasons. First, disease management is either medical or surgical. Vascular causes show the highest rate of recovery and the shortest recovery period compared to other factors. Cranial nerve VI is the most commonly involved region, followed by III in this disease.

\section{References}

1. Camargo GB, Hida WT, Goldchmit M, Uesugui CF, Souza-Dias CR. Paralytic strabismus: review of 24 years at Santa Casa de São Paulo". Brazilian Arch Ophthalmol. 2007;70(4):585-7.

2. Rucker CW. Paralysis of the third, fourth and sixth cranial nerves. Am J Ophthalmol. 1958;46(6):787-94.

3. Rucker CW. The causes of paralysis of the third, fourth and sixth cranial nerves. Am J Ophthalmol. 1966;61(5 Pt 2):1293-8.

4. Rush JA, Yoauge BR. Paralysis of cranial nerves III, IV and VI. Cause and prognosis in 1,000 cases. Arch Ophthalmol. 1981;99(1):76-9. 
5. Kodsi SR, Younge BR. Acquired oculomotor, trochlear and abducent cranial nerve palsies in pediatric patients. Am J Ophthalmol. 1992;114(5):568-74.

6. Richard BW, Jones FR Jr, Younge BR. Causes and prognosis in 4,278 cases of paralysis of the oculomotor, trochlear, and abducens cranial nerves. Am J Ophthalmol. 1992;113(5):489-96.

7. Prieto-Diaz J, Souza-Dias C. In: Estrabismo 3a Ed. São Paulo: Roca. 1996;377-442.

8. Avó DS, Gurgel DPA, Salomão SR. Estrabismo paralítico: Um estudo de 168 casos. Bol Bras Ortóp. 1986;12:28-34.

9. Abreu FJQ, Abreu Filho JMPQ, Abreu JMPQ. Paresias e paralisias dos nervosoculomotores. Estudo retrospectivo e prospectivo - período de 30 anos. Rev Bras Oftalmol. 1993;52(4):19-25.

10. Sydnor CF, Seaber JH, Buckley EG. Traumatic superior oblique palsies. Ophthalmol. 1982;89(2):134-8.

11. Von Noorden GK, Murray E, Wong SY. Superior oblique paralysis. A review of 270 cases. Arch Ophthalmol. 1986;104(12):1771-6.

12. Robb RM. Idiopathic superior oblique palsies in children. J Pedriatr Ophthalmol Strabismus. 1990;27(2):669.

13. Souza-Dias C. Congenital IV nerve palsy in Duane's syndrome until disproven. Binocular Vision Q. 1992;7(2):70-7.

14. Peragallo JH, Bruce BB, Hutchinson AK, Lenhart PD, Biousse V, Newman NJ, et al. Functional and motor outcomes of strabismus surgery for chronic isolated adult sixth nerve palsy. Neuro-Ophthalmol. 2014;38(6):320-5.

15. Kim K, Noh SR, Kang MS, Jin KH. Clinical course and prognostic factors of acquired third, fourth, and sixth cranial nerve palsy in Korean patients. Korean J Ophthalmol. 2018;32(3):221-7. 